\title{
Lipid peroxidation in kidney and testis tissues in experimental hypothyroidism: the role of zinc
}

\author{
Baltaci AK ${ }^{1}$, Mogulkoc R ${ }^{1}$, Ayyildiz $\mathrm{M}^{2}$, Kafali E ${ }^{3}$, Koyuncuoglu $\mathrm{T}^{1}$ \\ Selcuk University, Selcuklu Medical School Department of Physiology, Konya, Turkey. \\ rasimmogulkoc@yahoo.com
}

\begin{abstract}
The aim of the present study was to determine the effect of zinc supplementation and zinc deficiency on the lipid peroxidation in the testis and kidney tissues of rats with experimentally induced hypothyroidism. The experimental Groups were formed as follows: 1 - Control; 2 - Sham-Hypothyroidism; 3 - Hypothyroidism (intraperitoneal administration of $10 \mathrm{mg} / \mathrm{kg} / \mathrm{day}$ PTU for 4 weeks); 4 - Hypothyroidism $+3 \mathrm{mg} / \mathrm{kg} / \mathrm{day}$ zinc supplementation (4 weeks); 5 - Hypothyroidism + zinc deficiency (4 weeks).

The examination of the study results revealed that hypothyroidism in testis and kidney tissues increased MDA levels and decreased GSH levels $(p<0.001)$. Zinc supplementation in addition to hypothyroidism, however, reduced the increased MDA amount and elevated GSH levels $(p<0.001)$. Zinc deficiency together with hypothyroidism, on the other hand, was found to produce the opposite results $(p<0.001)$.

The results of the study indicated that experimental hypothyroidism caused lipid peroxidation in kidney and testis tissues. Zinc deficiency together with hypothyroidism made lipid peroxidation more evident, while zinc supplementation significantly inhibited the increased oxidative stress by activating the antioxidant system (Tab. 1, Ref. 24). Text in PDF www.elis.sk.

Key words: hypothyroidism, kidney, testes, MDA, GSH, zinc.
\end{abstract}

Oxidative stress, which arises from the impairment of the balance between free radical production and antioxidant defence mechanisms, is a critical pathogenic mechanism in various diseases $(1,2)$. Free radicals are known to damage all cellular structures (3). Mitochondria are the major production sources of free oxygen radicals and the radicals that originate from mitochondria lead to the oxidation of cellular structures like carbohydrates, lipids and proteins, causing organ dysfunctions (2). Reactive oxygen species are also known to have a part in the pathogenesis of thyroid dysfunctions (4). Thyroid hormones are the essential endocrine regulators of the metabolic status. They also have a deep impact on mitochondria, which are responsible for cellular adenosine triphosphate production (5). It has been established in various studies that the changes in thyroid hormone metabolism affect oxidant and antioxidant systems in different ways. Venditti et al (6) reported that $T_{3}$ treatment increased oxygen consumption and $\mathrm{H}_{2} \mathrm{O}_{2}$ production, while Cano-Europa and colleagues (7) found that hypothyroidism induced by methimazole or thyroidectomy caused cellular damage in rats and that this damage could not be corrected by antioxidant systems. However, it was also established

${ }^{1}$ Selcuk University, Selcuklu Medical School Department of Physiology, Konya, Turkey, ${ }^{2}$ Ondokuz Mayis University, Medical School Department of Physiology, Samsun, Turkey, and ${ }^{3}$ Selcuk University, Selcuklu Medical School Department of General Surgery, Konya, Turkey

Address for correspondence: R. Mogulkoc, Dr, Selcuk University, Selcuklu Medical School Department of Physiology, 42075, Konya, Turkey.

Acknowledgement: This study was supported in part by SUBAPK (Scientific Research Project Coordinator of Selcuk University). Project number is TF 2002-086. in another study that the effect caused by propylthiouracil (PTU) administration on the oxidant and antioxidant systems changed in a time-dependent manner (8).

Zinc, an important element, is not only involved in the structure of many enzymes, but also has strong antioxidant effects. It has been reported in several research studies examining the antioxidant effects of zinc that it inhibits the damage induced by various procedures in the testis and kidney tissues $(9,10)$.

The examination of the Medline research did not produce any study investigating the effect of zinc supplementation and zinc deficiency on the oxidant and antioxidant systems together with experimental hypothyroidism. The objective of the present study was to determine the effect of zinc deficiency and zinc supplementation on testis and kidney tissue MDA and GSH levels in experimental hypothyroidism induced by 4-week PTU injection.

\section{Materials and methods}

\section{Experimental animals and their diet}

This study was carried out at Selcuk University Experimental Medicine Application and Research Centre on rats acquired from the same institution. Study protocol was approved by local ethic committee. The study included 50 Sprague-Dawley adult male rats, which were allocated into the Groups as follows:

Group 1 (n: 10) General Control Group: The Group which was not subjected to any procedure and fed on a normal diet.

Group 2 (n: 10) Sham-hypothyroidism Group: The Group which was injected with $1 \mathrm{ml} / 250 \mathrm{~g} /$ day intraperitoneal (ip) serum physiologic for 4 weeks. 
Group 3 (n: 10) Hypothyroidism (PTU) Group: The Group which was administered $10 \mathrm{mg} / \mathrm{kg} /$ day intraperitoneal PTU for 4 weeks.

Group 4 (n: 10) Hypothyroidism (PTU) + Zinc Supplemented Group: The Group which was administered $10 \mathrm{mg} / \mathrm{kg} /$ day intraperitoneal (ip) PTU and supplemented with $3 \mathrm{mg} / \mathrm{kg} /$ day zinc sulphate for 4 weeks.

Group 5 (n: 10) Hypothyroidism (PTU) + Induced Zinc Deficiency Group: The Group which was administered $10 \mathrm{mg} / \mathrm{kg} /$ day intraperitoneal (ip) PTU and fed on a zinc deficient diet (0.65 $\mathrm{ppm} /$ zinc/gr/diet) for 4 weeks.

In order to minimize zinc contamination, the experimental animals were fed in special steel cages, which were cleaned by washing on a daily basis. The feed was provided in special steel bowls and water (bidistilled water to the animals fed on a zinc-deficient diet and tap water to others) in glass feeding bottles.

\section{Propylthiouracil administration}

In order to induce hypothyroidism, 6-n-propyl-2-thiouracil "PTU" (Sigma Chemical Co., Dorset, UK) was dissolved in 0.1 $\mathrm{N} \mathrm{NaOH} / 0.9 \% \mathrm{NaCl}$ and administered in the form of a $10 \mathrm{mg} /$ $\mathrm{kg} /$ day ( $1 \mathrm{ml} / 250 \mathrm{~g}$ ) intraperitoneal (ip) injection for 4 weeks.

Serum physiologic injection

Experimental animals were injected with serum physiologic as $1 \mathrm{ml} / 250 \mathrm{~g}$ through intraperitoneal route for 4 weeks as placebo.

Zinc sulphate supplementation

Likewise, zinc sulphate was administered, after being dissolved in distilled water ( 1 gram in $210 \mathrm{ml}$ ), as a $3 \mathrm{mg} / \mathrm{kg} /$ day intraperitoneal injection. Zinc sulphate supplementation was performed at 09.00 a.m. for a period of 4 weeks.

\section{Biochemical analyses}

Tissue MDA analyses: In order to obtain a $10 \%$ homogenate, testes and kidney tissue samples were homogenised with $150 \mathrm{mMol}$ $\mathrm{KCl}$ at $+4{ }^{\circ} \mathrm{C}$ (Microsan Ultrasonic Cell Disruptor Misonic).Two $\mathrm{ml} \mathrm{HClO}_{4}$ was added to $2 \mathrm{ml}$ of homogenate, which was then centrifuged at $3000 \mathrm{rpm}$ for 15 minutes. MDA level was evaluated in the supernatant. Then, $3 \mathrm{ml} \mathrm{H}_{3} \mathrm{PO}_{4}, 1 \mathrm{ml} 0.675 \%$ thiobarbituric acid and $0.5 \mathrm{ml}$ of homogenate were mixed, and the mixture was kept in a boiling water bath for 45 minutes (11). MDA levels were measured at $532 \mathrm{~nm}$ and determined as $\mathrm{nmol} / \mathrm{ml}$.

Tissue GSH analyses: In order to obtain a $10 \%$ homogenate, testes and kidney tissue samples were homogenised with 150 $\mathrm{mMol} \mathrm{KCl}$ at $+4{ }^{\circ} \mathrm{C}$ (Microsan Ultrasonic Cell Disruptor Misonic) and then centrifuged at $3000 \mathrm{rpm}$ for 15 minutes. GSH level in the supernatant was determined (12). Tissue protein concentra- tion was determined by biuret method. GSH level was established as $\mathrm{mg} / \mathrm{dl}$.

\section{Statistical evaluations}

Statistical evaluation of data was performed using a computer package software. The arithmetic means and standard deviations of all parameters were calculated. Variance analysis was used to determine differences among the groups. Duncan method was used to establish the differences between the group means in the variance analysis results, which were found statistically significant. Correlation coefficients were calculated to determine whether there was a significant correlation among the study parameters.

\section{Results}

The examination of testis tissue MDA levels in the study showed that this parameter was higher in the hypothyroidism + zinc-deficient Group (Group 5) than all other groups ( $<<0.001$ ). The hypothyroidism Group (Group 3) also had higher MDA values than the Groups 1, 2 and 4 ( $p<0.001)$. MDA values in the Group 4 were higher than those in the Groups 1 and 2, but the difference was not statistically significant. When GSH levels in the testis tissue were examined, the zinc-supplemented Group (Group 4) was found to have the highest GSH values ( $<<0.001$ ). The Groups 1 and 2 had testis tissue GSH values higher than the Groups 3 and 5 (p $<0.001)$ (Tab. 1).

Concerning kidney tissue MDA levels, the zinc-deficient Group 5 was found to have the highest, and control and shamhypothyroidism groups were found to have the lowest kidney tissue MDA levels $(\mathrm{p}<0.001)$. MDA values in Group 4 were higher than those in Groups 1 and 2, but lower than the levels in Groups 3 and 5 ( $p<0.001)$. As for GSH levels in this tissue, it was seen that this parameter was at the highest level in the zinc-supplemented Group (Group 4) and at the lowest level in the Group fed on a zinc-deficient diet (Group 5) (p < 0.001) (Tab. 1). Hypothyroidism Group (Group 3) had kidney tissue GSH values lower than the control Group (Group 1) and sham-hypothyroidism Group (Group 2) $(\mathrm{p}<0.001)$.

\section{Discussion}

It has been established as the result of an overall evaluation of the study results that levels of MDA, an indicator of tissue damage in experimental hypothyroidism induced by 4-week PTU administration, increased, while levels of GSH, an indicator of antioxidant defence, decreased. Zinc supplementation together with

Tab. 1. MDA (nmol/ml) and GSH (mg/dl) Levels of Study Groups.

\begin{tabular}{|c|c|c|c|c|}
\hline Groups & Testes (MDA) & Kidney (MDA) & Testes (GSH) & Kidney (GSH) \\
\hline $1-$ Control & $14.28 \pm 0.77^{\mathrm{C}}$ & $15.22 \pm 2.21^{\mathrm{D}}$ & $17.28 \pm 1.31^{\mathrm{B}}$ & $13.56 \pm 1.62^{\text {в }}$ \\
\hline 2 - Sham-hypothyroid & $16.37 \pm 1.69^{\mathrm{C}}$ & $16.67 \pm 1.63^{\mathrm{D}}$ & $17.67 \pm 0.92^{\text {в }}$ & $14.24 \pm 2.07^{\text {в }}$ \\
\hline 3 - Hypothyroid & $41.54 \pm 1.97$ в & $32.61 \pm 5.39^{\text {в }}$ & $8.94 \pm 0.51^{\mathrm{C}}$ & $10.31 \pm 2.83^{\mathrm{C}}$ \\
\hline 4 - Hypothyroid + Zinc Supplemented & $22.18 \pm 1.85^{\mathrm{C}}$ & $22.55 \pm 1.36^{\mathrm{C}}$ & $24.51 \pm 1.29^{\mathrm{A}}$ & $26.51 \pm 3.35^{\mathrm{A}}$ \\
\hline 5 - Hypothyroid + Zinc Deficient & $67.75 \pm 3.22^{\mathrm{A}}$ & $55.28 \pm 5.79^{\mathrm{A}}$ & $6.48 \pm 0.83^{\mathrm{C}}$ & $6.55 \pm 0.91^{\mathrm{D}}$ \\
\hline
\end{tabular}

Means with different superscripted letters in the same column have statistical significance $(\mathrm{p}<0.001)$. 
experimental hypothyroidism reduced the damage in the tissues, but zinc deficiency further aggravated the concerned damage. Changes in the amount of thyroid hormones produce different effects. Erdamar and colleagues (4) found in their study that MDA levels were elevated in both hypothyroidism and hyperthyroidism. It is argued that elevated reactive oxygen species cause an impairment in the antioxidant defence system of patients with hypothyroidism and hyperthyroidism. Thus, thyroid hormones have critical effects on oxidative stress and antioxidant defence. It has also been shown that free radical reactions rapidly increase and antioxidant defence is suppressed in hypothyroidism caused by iodine deficiency (13). In the same vein, Sawant et al (14) reported in their study that lipid peroxidation did not change in hyperthyroidism, but significantly increased in hypothyroidism. It has been shown in the same study that glutathione peroxidase and GSH levels remained unchanged. There are also studies demonstrating that hypothyroidism induced by thyroidectomy produced a protective effect against ischemic-reperfusion injury (15). However, one-week thyroxin administration to rats with hypothyroidism increased oxidant stress. In our study, hypothyroidism induced by 4-week PTU administration elevated kidney tissue MDA levels and inhibited GSH levels. Our results are parallel to the reports of increased oxidant damage in hypothyroidism. However, it was established in the previous study that hypothyroidism caused by a short-term (2-week) PTU administration reduced MDA and GSH levels (16). These different results in the concerned study may be associated with the duration of administration. While a 4-week administration was performed in our study, the concerned study used a 2-week administration.

The results of our study about the testis tissue revealed that MDA levels in this tissue increased and GSH levels decreased, similar to the kidney tissue. Zamoner and colleagues (17) reported in their study that congenital hypothyroidism stimulated by PTU reduced oxygen consumption in the testis tissue of immature rats, did not change lipid peroxidation, but the decrease in enzymatic and non-enzymatic defence caused biochemical changes. In a study by Sahoo et al (18), temporary hypothyroidism reduced mitochondrial peroxidation in rat testis tissues, while permanent hypothyroidism increased lipid peroxidation and protein carbonylation. In another study, Senatore et al (19) found that hypothyroidism in rats increased lipid peroxidation in testis tissue. In the same vein in our study, it was established that the amounts of hydrogen peroxide and protein carbonyl, parameters of oxidative stress, increased in the testis tissues of rats with hypothyroidism induced by PTU (20). Elevated MDA showing lipid peroxidation and decreased GSH showing a decline in the antioxidant defence in the testis tissues in hypothyroidism are similar to the results of the researchers cited above.

Zinc supplementation and zinc deficiency in addition to experimental hypothyroidism induced by PTU administration, which constituted the second part of our study, were seen to significantly affect kidney and testis tissue MDA and GSH levels, and consequently oxidant and antioxidant systems of rats. In fact, the increase in MDA and the decrease in GSH levels caused by hypothyroidism were considerably restored by zinc supplementation. Zinc deficiency, on the other hand, aggravated lipid peroxidation. The antioxidant characteristic of zinc has thus been demonstrated in this study. Similarly, Tang et al (21) reported in their study that zinc prevented pathological renal changes in diabetic rats. In the same vein, Amer et al (22) demonstrated the antioxidant characteristics of zinc in old rats. It was also reported in previous studies that zinc metallothionein offered a significant degree of protection in the kidney (10) and testis (9). In addition to its direct antioxidant characteristics, zinc may have brought about these effects through its effect on thyroid function, and therefore on thyroid hormone levels. Actually, we have found in our previous studies that zinc deficiency reduced, while zinc supplementation elevated thyroid hormones $(23,24)$. Zinc supplementation in addition to hypothyroidism significantly reduced MDA levels in both tissues, whereas zinc deficiency brought about critical increases in this parameter. The levels of GSH, which has an antioxidant character, however, were significantly inhibited in zinc deficiency and critically increased with zinc supplementation.

\section{Conclusions}

Results of the present study indicated that lipid peroxidation in kidney and testis tissues increased in experimental hypothyroidism induced by 4-week PTU administration in rats. This increase in lipid peroxidation was aggravated by zinc deficiency, while zinc supplementation in addition to hypothyroidism significantly prevented tissue damage by reducing MDA levels and increasing GSH levels.

\section{References}

1. Mancini A, Festa R, Di Donna V, Leone E, Littarru GP, Silvestrini A, Meucci E, Pontecorvi A. Hormones and antioxidant systems: role of pituitary and pituitary-dependent axes. J Endocrinol Invest 2010; 33: 422-433.

2. Torun AN, Kulaksizoglu S, Kulaksizoglu M, Pamuk BO, Isbilen E, Tutuncu NB. Serum total antioxidant status and lipid peroxidation marker malondialdehyde levels in overt and subclinical hypothyroidism. Clin Endocrinol (Oxf) 2009; 70: 469-474.

3. Chandra AK, Sinha S, Choudhury SR. Thyroxine induced stress and its possible prevention by catechin. Indian J Exp Biol 2010; 48: 559-565.

4. Erdamar H, Demirci H, Yaman H, Erbil MK, Yakar T, Sancak B, Elbeg S, Biberoglu G, Yetkin I. The effect of hypothyroidism, hyperthyroidism, and their treatment on parameters of oxidative stress and antioxidant status. Clin Chem Lab Med 2008; 46: 1004-1010.

5. Harper ME, Seifert EL. Thyroid hormone effects on mitochondrial energetics. Thyroid 2008; 18: 145-156.

6. Venditti P, Chiellini G, Di Stefano L, Napolitano G, Zucchi R, Columbano A, Scanlan TS, Di Meo S. The TRbeta-selective agonist, GC-1, stimulates mitochondrial oxidative processes to a lesser extent than triiodothyronine. J Endocrinol 2010; 205: 279-289.

7. Cano-Europa E, Blas-Valdivia V, Lopez-Galindo GE, Franco-Colin M, Pineda-Reynoso M, Hernandez-Garcia A, Ortiz-Butron R. Methimazole-induced hypothyroidism causes alteration of the REDOX environment, oxidative stress, and hepatic damage; events not caused by hypothyroidism itself. Ann Hepatol 2010; 9: 80-88. 
8. Bhanja S, Chainy GB. PTU-induced hypothyroidism modulates antioxidant defence status in the developing cerebellum. Int J Dev Neurosci 2010; 28: 251-262.

9. Bonda E, Włostowski T, Krasowska A. Testicular toxicity induced by dietary cadmium is associated with decreased testicular zinc and increased hepatic and renal metallothionein and zinc in the bank vole (Clethrionomys glareolus). Biometals 2004; 17: 615-624.

10. Iqbal M, Noor R, Mizuno R, Okada S. Protective role of zinc-metallothionein (Zn-MT) in iron nitrilotriacetate (Fe-NTA)-induced renal oxidative damage. Redox Rep 2003; 8: 163-167.

11. Uchiyama M, Mihara M. Determination of malondyaldehyde precurser in tissues by thiobarbituric acid test. Anal Biochem 1977; 86: 271-278.

12. Elman GL. Tissue sulfhydryl Groups. Arch Biochem Biophys 1959; 82: $70-77$.

13. Tuchak OI, Voronych-Semchenko NM. The changes of free radical lipid peroxidation, antioxidant system activity, nitrogen oxide level in iodo-deficient hypothyrosis. Fiziol Zh 2008; 54: 54-57.

14. Sawant BU, Nadkarni GD, Thakare UR, Joseph LJ, Rajan MG. Changes in lipid peroxidation and free radical scavengers in kidney of hypothyroid and hyperthyroid rats. Indian J Exp Biol 2003; 41: 1334-1337.

15. Paller MS. Hypothyroidism protects against free radical damage in ischemic acute renal failure. Kidney Int 1986; 29: 1162-1166.

16. Mogulkoc R, Baltaci AK, Oztekin E, Ozturk A, Sivrikaya A. Shortterm thyroxine administration leads to lipid peroxidation in renal and testicular tissues of rats with hypothyroidism. Acta Biol Hung 2005; 56: 225-132.
17. Zamoner A, Barreto KP, Filho DW, Sell F, Woehl VM, Guma FC, Pessoa-Pureur R, Silva FR. Propylthiouracil-induced congenital hypothyroidism upregulates vimentin phosphorylation and depletes antioxidant defenses in immature rat testis. J Mol Endocrinol 2008; 40: 125-135.

18. Sahoo DK, Roy A, Bhanja S, Chainy GB. Hypothyroidism impairs antioxidant defence system and testicular physiology during development and maturation. Gen Comp Endocrinol 2008; 156: 63-70.

19. Senatore V, Cione E, Gnoni A, Genchi G. Retinoylation reactions are inversely related to the cardiolipin level in testes mitochondria from hypothyroid rats . J Bioenerg Biomembr 2010; 42: 321-328.

20. Choudhury S, Chainy GB, Mishro MM. Experimentally induced hypo-and hyper-thyroidism influence on the antioxidant defence system in adult rat testis. Andrologia 2003; 35: 131-140.

21. Tang Y, Yang Q, Lu J, Zhang X, Suen D, Tan Y, Jin L, Xiao J, Xie R, Rane M, Li X, Cai L. Zinc supplementation partially prevents renal pathological changes in diabetic rats. J Nutr Biochem 2010; 21: 237-246.

22. Amer MA. Modulation of age-related biochemical changes and oxidative stress by vitamin $\mathrm{C}$ and glutathione supplementation in old rats. Ann Nutr Metab 2002; 46: 165-168.

23. Baltaci AK, Mogulkoc R, Kul A, Bediz CS, Ugur A. Opposite effects of zinc and melatonin on thyroid hormones in rats. Toxicology 2004; 195: 69-75.

24. Baltaci AK, Mogulkoc R, Bediz CS, Kul A, Ugur A. Pinealectomy and zinc deficiency have opposite effects on thyroid hormones in rats. Endocr Res 2003; 29: 473-841. 